Instructions for authors, subscriptions and further details:

http://brac.hipatiapress.com

\title{
La Ficción del Exilio: la Poética como Estrategia Narrativa en la Obra de Mona Hatoum \\ Yassine Chouati ${ }^{1}$
}

1) Departamento de Dibujo, Facultad de Bellas Artes, Universidad de Sevilla

Date of publication: February $3^{\text {rd }}, 2021$

Edition period: October 2020 - February 2021

To cite this article: Chouati, Y. (2021). La Ficción del Exilio: la Poética como Estrategia Narrativa en la Obra de Mona Hatoum. Barcelona, Research, Art, Creation, 9(1), pp. 83-99. doi: 10.17583/brac.2021.4233

To link this article: http://dx.doi.org/10.17583/brac.2021.4233

PLEASE SCROLL DOWN FOR ARTICLE

The terms and conditions of use are related to the Open Journal System and to Creative Commons Attribution License (CC-BY). 
BRAC - Barcelona Research Art Creation. Vol. 9 No. 1, February 2021, pp. 83-99

\section{The Fiction of Exile: Poetics as a Narrative Strategy in the Work of Mona Hatoum}

Yassine Chouati

Departamento de Dibujo, Facultad de Bellas Artes, Universidad de Sevilla

(Received: 7 April 2019; Accepted: 26 October 2020; Published: 3 February 2021)

\section{Abstract}

Starting from the idea formulated by Edward Said that the experience of being homeless generates a distanced reading of historical facts, we propose the present study, which consists of analyzing how exile intervenes in the narrative strategies of the Palestinian British artist Mona Hatoum. Our purpose is to create a theoretical framework that helps us understand the reason for her formal and aesthetic choices, where the use of fiction and the duality between attraction and repulsion stand out. The strategy used consists of delving into the paradoxical relationships of Hatoum's experience as an Arab artist of the diaspora through symmetries and parallels with historical references who experienced similar situations. This strategy is used as an introduction and contextualization of the work of our artist under study in order to understand her discursive development, her role as speaker of the Arab sociopolitical reality in the heart of the Western world and the value of the vision that it provides us about said reality.

Keywords: Art, exile, distance, poetics, fiction

2021 Hipatia Press

ISSN: 2014-8992

DOI: $10.17583 /$ brac.2021.4233

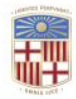

UNIVERS ITAT ${ }_{\text {DE }}$ BARCELONA
Hipatia Press

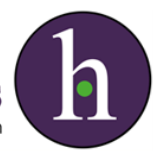


BRAC - Barcelona Research Art Creation. Vol. 9 No. 1, February 2021, pp. 83-99

\section{La Ficción del Exilio: la Poética como Estrategia Narrativa en la Obra de Mona Hatoum}

Yassine Chouati

Departamento de Dibujo, Facultad de Bellas Artes, Universidad de Sevilla

(Recibido: 7 abril 2019; Aceptado: 26 octubre 2020; Publicado: 3 febrero 2021)

\section{Resumen}

A partir de la idea que formula Edward Said de que la experiencia de carecer de hogar genera una lectura distanciada de los hechos históricos, planteamos el presente estudio, que consiste en analizar cómo interviene el exilio en las estrategias narrativas de la artística británico palestina Mona Hatoum. Nuestro propósito es crear un marco teórico que nos ayude a comprender el porqué de sus elecciones formales y estéticas, donde destacan el uso de la ficción y la dualidad entre la atracción y la repulsión. La estrategia empleada consiste en profundizar en las relaciones paradójicas de la experiencia de Hatoum como artista árabe de la diáspora a través de simetrías y paralelismos con referentes históricos que experimentaron semejantes situaciones. Esta estrategia es empleada como introducción y contextualización del trabajo de nuestra artista objeto de estudio con el fin de entender su desarrollo discursivo, su papel como altavoz de la realidad sociopolítica árabe en el corazón del mundo occidental y el valor que posee la visión que nos proporciona sobre dicha realidad.

Palabras clave: Arte, exilio, distancia, poética, ficción 


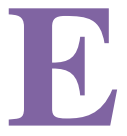

dward Said en su ensayo Poder, política y cultura (2020, p. 474-571) nos habla de un exilio del exilio, donde nos indica un necesario desapego del hogar como referencia realista que ciega y crea doctrinas. Para él, la conciencia exiliada no reside en la idea del hogar, sino en asumir que cada sujeto genera su propia percepción del mundo. A partir de ahí, se entiende que cualquier anhelo a la tierra y a la patria como lugar estable al que se quiere retornar es una concepción no real e imaginaria, que no existe de manera tangible, sino que es pura fantasía. Por ende, el sujeto exiliado podría pasar toda una vida llorando su pérdida y aferrado a los recuerdos. Es decir, aferrado a aquello que considera María Zambrano como "metafísica de la ausencia", una condición que no concierne solo a los exiliados sino a todo ser humano. Según ella, el ser humano ante la imposibilidad de hallar un espacio en el que arraigar su existencia añora el pasado como lugar perdido al que quiere conquistar (2019, p.32-33). No obstante, existe otro género del exilio, que es precisamente, el tipo que nos interesa en este estudio, el cual experimenta Hatoum. Es un exilio artístico e intelectual, donde "se enajena cualquier acceso inmediato a una identidad originaria o una tradición recibida" (Jahanbegloo, 2011, p.123). En palabras de Ramin Jahanbegloo, se trata de un alma exiliada difícil de definir, puesto que ya no forma parte totalmente de su cultura, pero tampoco es totalmente ajena a ella. Ahí, según Jahanbegloo, se preparan las condiciones idóneas para la construcción del diálogo con la diferencia. El sujeto exiliado consciente de su condición encuentra en la indefinición una oportunidad de establecer diálogos también con aquellos que se oponen al lugar y al papel de la interculturalidad y de la diversidad en sus sociedades. De modo que la distancia proporciona una suerte de mirada de conjunto que surge como consecuencia de la soledad, un proceso meditativo donde se encuentran nuevas formas de la razón en la interculturalidad, para así evitar el aislamiento (Adorno, 2001).

\section{Mona Hatoum: ¿Cuál es el Espacio que Ocupa un Creador en el Exilio?}

"La misión intelectual del exiliado, es contemplar la realidad a partir del desapego del exilio con discrepancias con las ideas cerradas" (Said, 2013, p. 192). Creando un paralelismo entre esta idea expresada por Said y la perspectiva artística de nuestra artista objeto de estudio llegamos a la 
conclusión de que existe en sus estrategias narrativas "una mirada de conjunto". Esta se cristaliza a nuestro parecer mediante el traslado intencionado del espectador a la parte íntima de lo introspectivo. Es decir, un traslado a ese estado melancólico, de incertidumbre e inestabilidad que supone estar en el margen y en medio de dos o tres identidades sólidas. Respecto a estar en medio o en el margen, entendemos que es una compleja convivencia entre la distancia en cuanto a la lectura de los hechos históricos que proporciona el exilio y la ruptura por dentro que supone el desarraigo. Adorno suscribió en este sentido que: "todo intelectual en el exilio, sin excepción, lleva una existencia dañada, y hace bien en reconocerlo si no quiere que se le haga saber de forma cruel desde el otro lado de las puertas herméticamente cerradas de su autoestimación" (2001, p. 29-30). La existencia dañada según Said en el mundo del arte de Hatoum es una especie de guía artística sin recorridos precisos, donde "la familiaridad y la extrañeza son encerrados juntos de la manera más extraña, adyacentes e irreconciliables al mismo tiempo" (Said, 2011, p. 107). En Interior Landscape (2007) vemos cómo Hatoum recrea el hogar como espacio mítico cargado de pérdida y violencia, del cual somos exiliados permanentemente, pero al que siempre estamos atraídos. Los objetos que podemos pensar que reconocemos su connotación, cortan y amenazan. Una cama de hierro con base de alambre de púas, una almohada suave, donde la artista dibuja con su pelo el mapa histórico de Palestina, una mesa vieja y frágil, un bolso construido con trozos de papel, una percha con forma del mapa de Palestina. Ningún objeto que conforma el espacio expositivo cumple su funcionalidad (véase la imagen: 1). En este punto, Hatoum altera lo cotidiano, buscando lo extraño (véase la imagen 2), es decir, un intento de generar códigos desplazados. La obra de Hatoum no elimina lo doméstico que desde una perspectiva connotacional nos podría remitir al espacio asignado a la mujer en el inconsciente colectivo. Ahí, presenta signos que connotan significados complejos sobre la situación de la mujer, pero también nos habla del exilio y del hogar como nostalgia y como espacio perdido, difícil de alcanzar. El propósito por lo tanto de trabajar desde la complejidad y la no representación lineal es poder ofrecer al espectador una experiencia compartida de dislocación, donde el sujeto artista se transforma en un espacio metafórico que nos invita a entrar como extraños en tierras extrañas. 


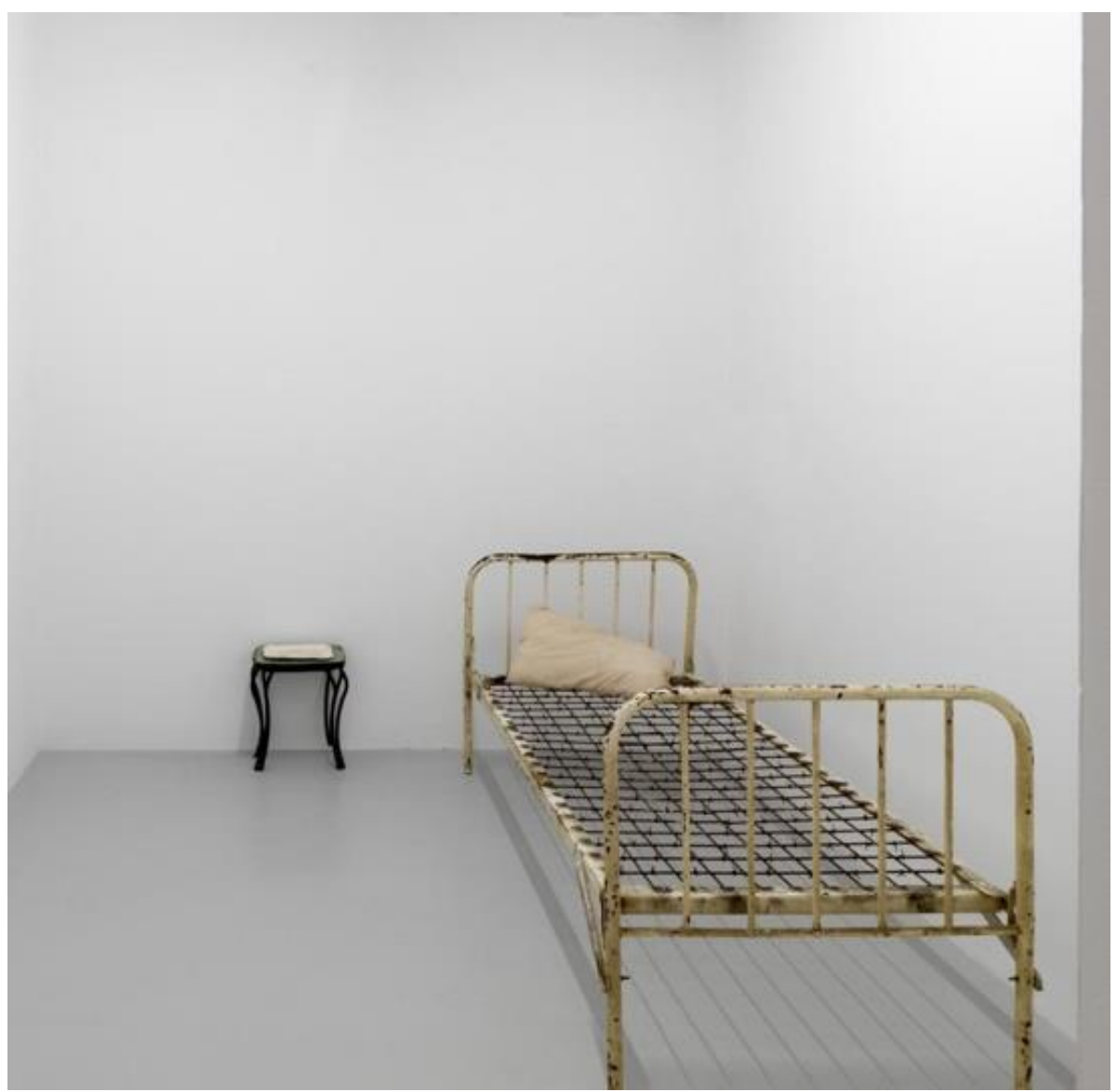

Imagen 1. Hatoum, M. (2007). Landscape interior [instalación, materialización variable].

El espacio al que nos invita Hatoum es un espacio introspectivo dedicado a "ajustar cuentas pendientes", donde se sobreponen dos dimensiones: la primera es visible-decorativa y la segunda invisible-grotesca y amenazante. Para alcanzar el clic y emocionar con la parte invisible, la artista nos invita a ir más allá del decorado. Ese compromiso no verbal lo encontramos de manera más evidente en The Light at the End. En ella, la artista teje como una araña un tramado de claves poéticas dispersas en el espacio, creando "un mundo visual que se burla de nosotros y nos convierte en presas" (Didi-Huberman, 2015, p. 19). En el espacio expositivo The Light at the End (1989) desde la distancia vemos una habitación vacía y oscura, pintada de rojo en la que solo se ve una simple cuadrícula rectangular incrustada en la pared. A medida que 
nos acercamos a la obra, aquello que parecía bello y de aspecto minimalista se convierte paulatinamente en algo caliente y sofocante. Hatoum en ningún momento nos impide caminar hasta la cuadrícula o incluso tocarla, tampoco nos informa que las barras que parecen pintadas son en realidad metales al rojo vivo que consiguen llegar a esa temperatura al estar conectados a la red eléctrica (véase la imagen 2). Esa inquietante situación se presenta también en Light Sentence (1992), a través del movimiento de la bombilla que hace que las sombras de los casilleros de malla de alambre estén en movimiento perpetuo, creando una sensación de que la habitación balancea sobre nosotros y que el suelo se mueve bajo nuestros pies (véase la imagen 3). Said en Reflexiones sobre el exilio (2013) expone que recurrir a ese tipo de estrategias desagradables tiene que ver con la necesidad del afán de venganza que se encuentra escondido en lo visible, aquello que parece bello y armónicamente perfecto. Para ello nos cita la Divina comedia de Dante, donde según él:

(...) Hasta la beatífica paz que se alcanza en el Paraíso presenta rasgos de su afán de venganza y la severidad del juicio personificado en el infierno. ¿Quién sino un exiliado como Dante, desterrado de Florencia, pensaría la eternidad como lugar donde ajustar cuentas pendientes?" (Said, 2013, p. 190).

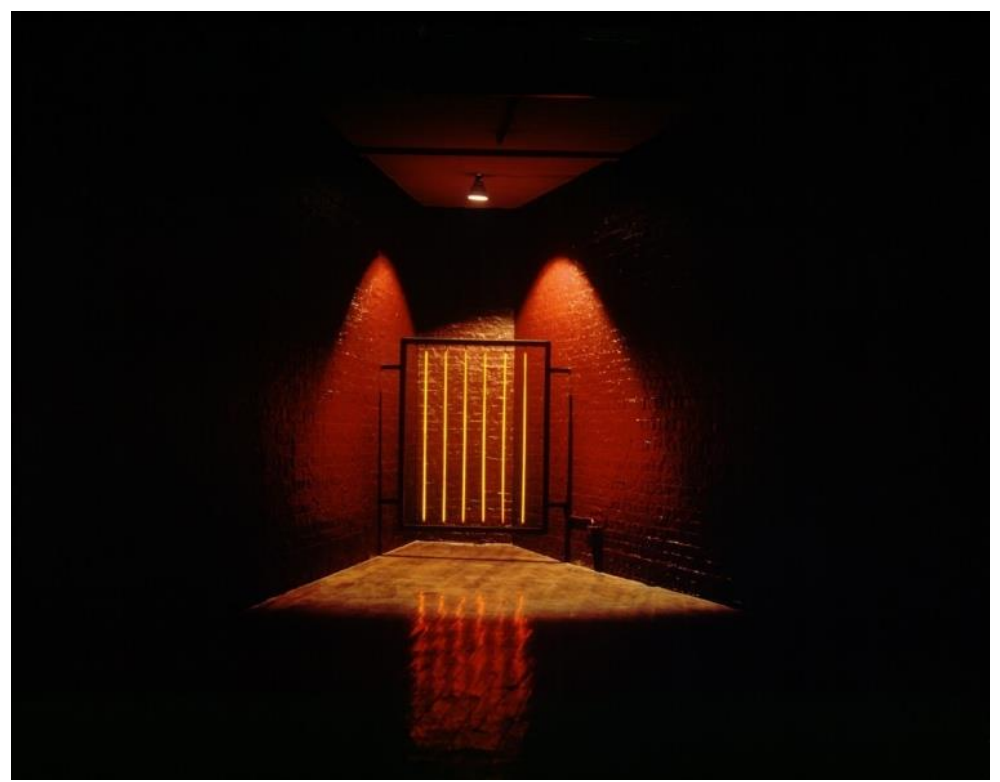

Imagen 2. Hatoum, M. (1989). The Light at the End, 1989 [Hierro, acero, latón, vidrio, aluminio y elementos eléctricos, Edición: 3/3]. 


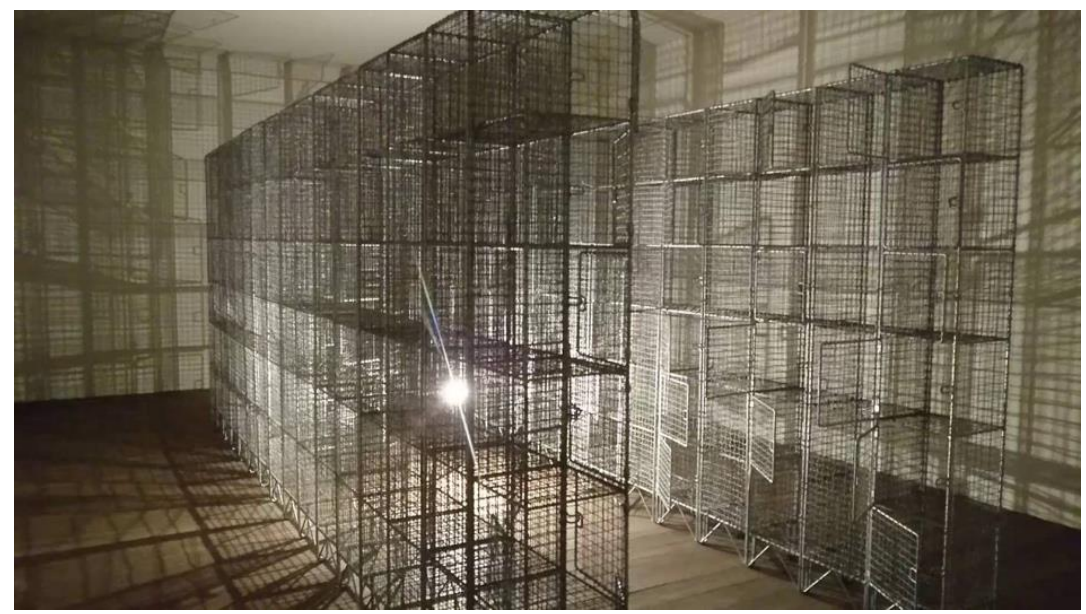

Imagen 3. Hatoum, M. (1989). The Light at the End, 1989 [Hierro, acero, latón, vidrio, aluminio y elementos eléctricos, Edición: 3/3].

\section{Interacción con el Espectador}

Como hemos podido ver en el anterior apartado, concretamente en el espacio no visible, donde existen posibilidades de vida y de interpretación, Hatoum, lejos de generar un arte de panfleto que explica la situación específica del exilio palestino, asume su subjetividad sobre los hechos históricos. Así, la provocación y la ruptura de la secuencia narrativa se convierten en el recurso por excelencia de la comunicación, una estrategia narrativa que le acompaña desde sus inicios en los años 80 en la Slade School de Londres. En la performance Don't smile you're on camera, realizada en 1980 en una sala de la Slade, Hatoum filma en directo a los espectadores, desplazando la cámara por sus cuerpos para luego proyectar en ellos imágenes de cuerpos desnudos que eran grabados paralelamente en otra sala (véase la imagen 4). La provocación que encontramos en esta obra va más allá de un simple ataque al espacio íntimo o la búsqueda de unas imágenes sexualizadas como afirma la artista en su conversación en 1998 con la artista Janine Antoni publicada en la revista Bomb. Hatoum con esta obra nos habla de la representación retórica de la información, que actúa dentro de nosotros y cosifica nuestros cuerpos sin darnos cuenta de su existencia. De hecho, es una reflexión sobre el envoltorio de nuestro mundo superficial y materialista que la artista presenta a través de su videoinstalación Corps étranger (1994). Aquí la filmación deja de rodar lo exterior para introducirse en lo interior. El cuerpo, en este caso, no 
es solo un soporte en el cual se proyectan imágenes, sino que también es un espacio donde nos podemos introducir, es un lugar vulnerable, pero al mismo tiempo extraño. Ya no es la imagen artificial que nos presentan los medios de masa, el cuerpo es líquido, cabelludo, desagradable, sangriento y extraño (véase la imagen 5). Ante la obra de Hatoum el espectador debe estar preparado a asumir su vulnerabilidad ante las cosas que lo rodean, dos maletas mostradas a ras del suelo, unidas por una gruesa masa de cabello humano que se derrama de un cuerpo que no está del todo contenido dentro de estas dos maletas (Traffic, 2002), un lugar (Home, 1999), al que no podemos acceder porque está bloqueada por minúsculos cables de acero tendidos a través de la puerta y unos utensilios de cocina conectados a una bombilla que produce un sonido zumbante y penetrante, y que revolotea inquietantemente al azar. Se trata de una representación figurada del mundo de los exiliados, un mundo en el que la vida se encuentra atrapada en los recuerdos bloqueados, donde todo parece extraño, gigante y amenazante. El sujeto en esa realidad frágil se encuentra inmerso en la angustia y anhelo de lo perdido.
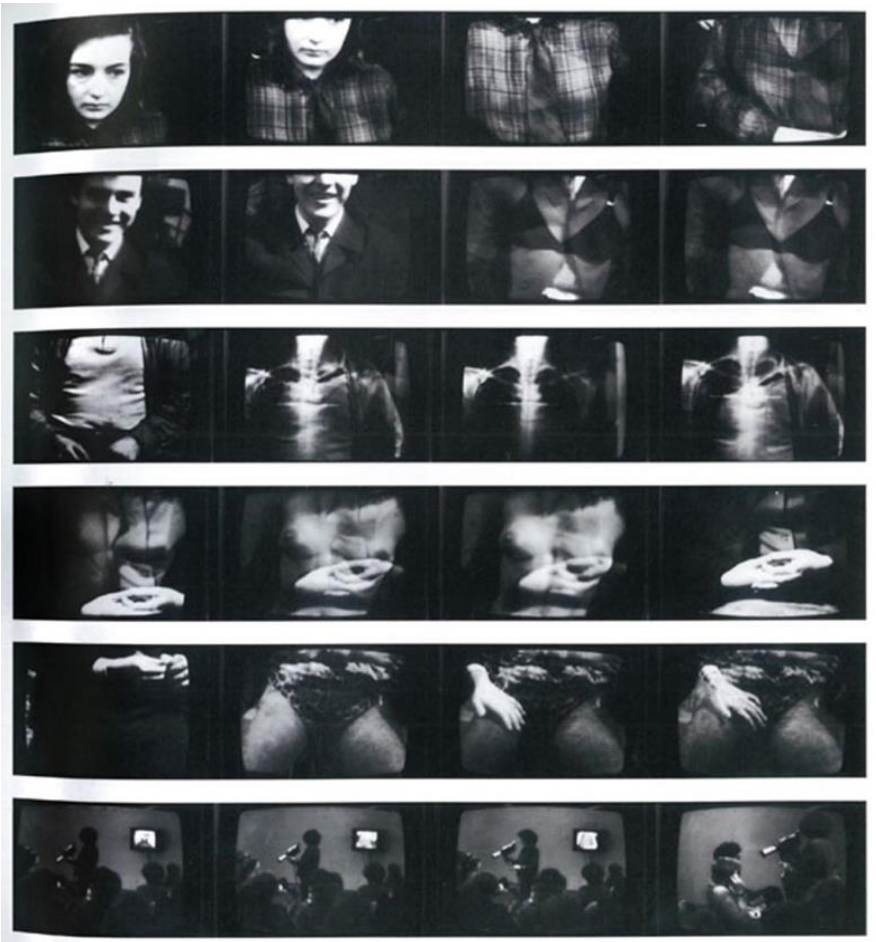

Imagen 4. Hatoum, M. (1980). Don't smile you're on camera [performance]. 


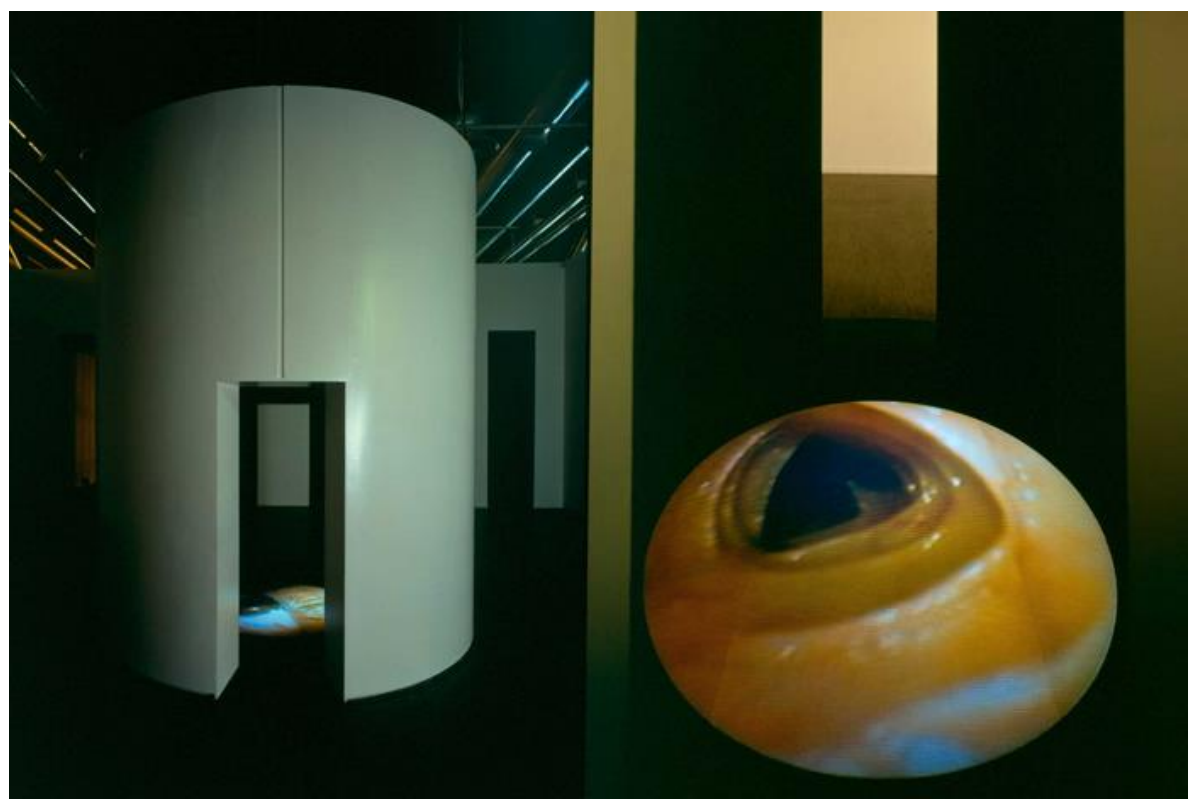

Imagen 5. Hatoum, M. (1994). Corps étranger [vista de instalación en Modern Art Oxford, 1998].

\section{La Búsqueda de lo Introspectivo: Evolución Discursiva}

Haciendo una revisión en la trayectoria de Hatoum desde sus inicios hasta la actualidad, observamos que dicho sentimiento de nostalgia mezclado con la impotencia que se manifiesta en su obra instalativa, es la piedra angular que influyó decisivamente en su evolución discursivo-estética. En obras de los años 80 tales como So Much I Want to Say (1983), The Negotiating Table (1983) o Roadworks (1985), reparamos una conciencia proyectada en problemáticas de orden universal (véase las imágenes 6, 7, 8). Sin embargo, con el tiempo dicho interés se ha ido canalizando gradualmente en el autoconocimiento que implicó indagar en la desestabilidad emocional que entraña la experiencia del desarraigo. Precisamente en este punto es donde la artista comienza a adoptar un lenguaje distanciado de la descripción lineal de los hechos, dando el salto a la manipulación física y al objeto tridimensional. Es decir, la mirada distanciada de la autodescripción inmediata que se observa en la obra de Hatoum es consecuencia de la nostalgia, que "es un orden de sentimiento que se adhiere a un objeto o ideal perdido, específicamente un hogar o patria" (Lauzon, 2009, p. 17). Esto explica la razón de las elecciones formales y narrativas que emplea Hatoum para construir sus piezas 
instalativas, donde no importa realmente la creación de nuevos objetos sino "lo que hacemos de los objetos que están a nuestra disposición" (Bourriaud, 2007, p. 22) Los objetos cotidianos, especialmente aquellos que hacen referencia al hogar se transforman en elementos extraños, inútiles y a veces amenazantes. Llegar a esta interpretación personal un tanto compleja de la experiencia del desarraigo, requiere una conciencia exiliada, es decir, darse cuenta del significado y la implicación emocional de la falta de hogar. De hecho, es una experiencia que sitúa al sujeto que la experimenta en la encrucijada de elegir entre aferrarse a la fantasía del hogar perdido o tomar la postura de la indefinición que formula Jahanbegloo, donde según él se preparan las condiciones idóneas para la construcción del diálogo con la diferencia. Esta última postura, como hemos podido comprobar en el trabajo de Hatoum, es la que le proporciona la mirada de conjunto, en la que no se buscan códigos definidos, sino turbulencias de significados con un aparente orden que recuerda a la anécdota que formula Brecht mediante su personaje "Kalle" quien responde a "Ziffel" en Narrativas completas, 7. Dialogos de refugiados diciendo:

(...) Yo en el fondo, soy partidario del orden. Pero un día vi una película con Charlie Chaplin en la que este iba guardando su ropa, etc.; en una maleta o mejor dicho iba tirando todo dentro, y al final cerró la tapa de golpe, y como muchas cosas quedaron a medio guardar, y el desorden le parecía inaguantable, cogió unas tijeras y empezó a cortar mangas y piernas a discreción, vale decir, todo cuando colgaba fuera (Brecht, 1994, p.14-15).

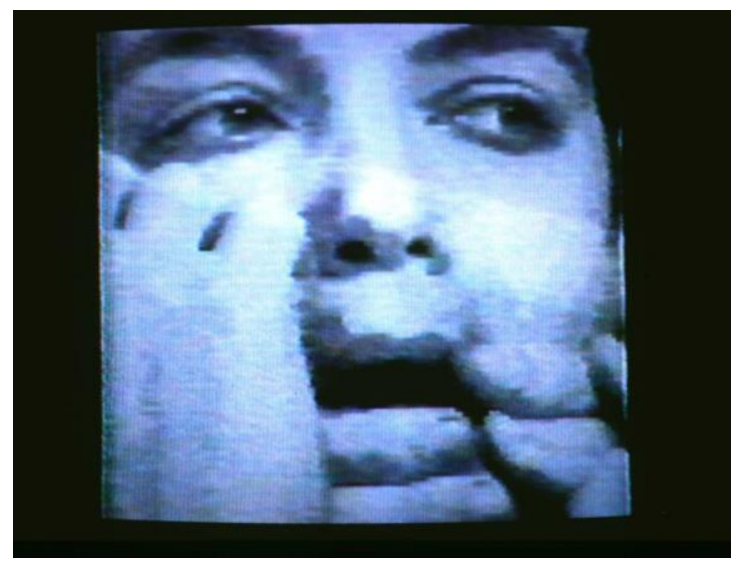

Imagen 6. Hatoum, M. (1983). So Much I Want to Say [video-performance]. 


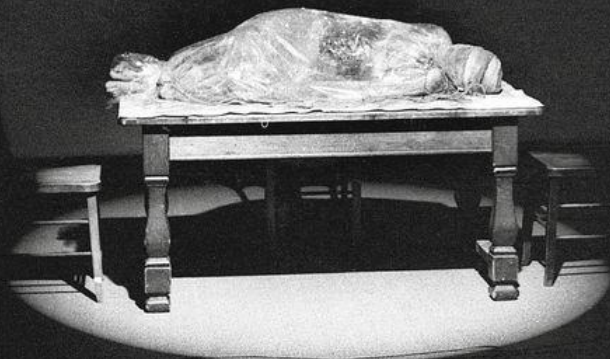

Imagen 7. Hatoum, M. (1983). The Negotiating Table [video-performance].

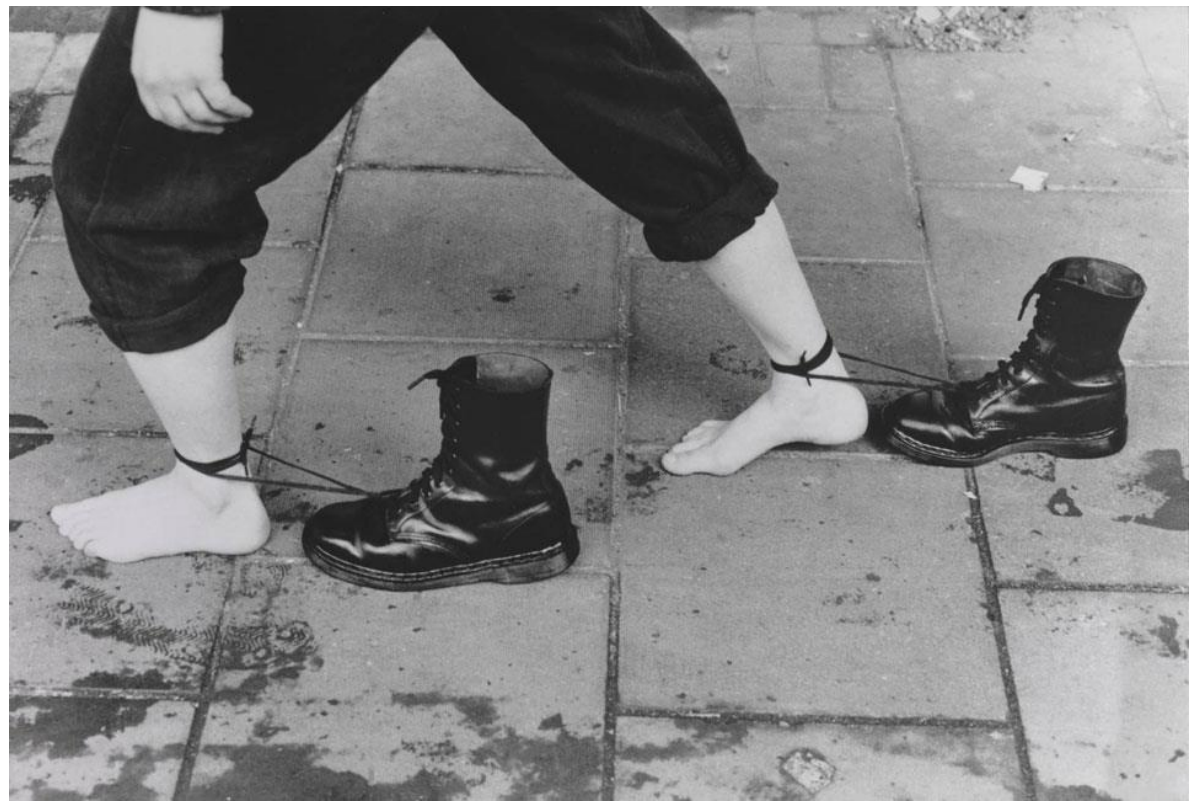

Imagen 8. Hatoum, M. (1985). Roadworks. [video-performance]. 


\section{Más allà de la Definición}

El autoconocimiento al que nos introduce Hatoum sobrepasa la definición identitaria que podemos examinar en algunos trabajos de investigación, que mantienen en muchas ocasiones una lectura superficial de su obra, tratando de forzar la pertenencia a una patria o un carácter estético determinado como podría ser el surrealismo, sin tener en consideración cuestiones relacionadas con la complejidad del exilio y/o la necesidad de establecer paralelismos que ayuden a profundizar en la obra de manera global. Más allá de una etiqueta o pertenencia a una identidad definida, en la obra de Hatoum se presenta la complejidad del exilio, donde interactúan deseos, necesidades e intenciones accesorias que se manifiestan "después de años de autoanálisis" (Antoni, 1988). Precisamente en ese empeño continuo de autoanálisis se manifiesta la turbulencia a la que hace referencia la exposición Turbulence llevada a cabo en Mathaf: Arab Museum of Modern Art (Doha, Katar) en 2014. El argumento de esta exposición consiste en representar la trayectoria de 30 años de trabajo de Hatoum como un desorden discursivo que rompe con lo esperado de una artista ordinaria que construye y defiende una coherencia específica. Es decir, existe una clara dificultad para trazar un hilo conductor temático o formal de la obra de Hatoum que tal vez, desde una mirada tradicional, podría ser considerado como una cuestión negativa debido a cierta falta de continuidad. ¿Acaso el sentimiento del exilio es claro? Sin lugar a duda, arrastrar una existencia dañada en el campo artístico se refleja en la falta de referencias estables y esto explica la variedad de intereses y formas estéticas que encontramos en la obra de nuestra artista objeto de estudio (Antoni, 1998). La idea que estamos exponiendo se manifiesta en las propias palabras de Hatoum, donde confirma que su obra no habla solo de la problemática del exilio, puesto que el exilio como experiencia engloba diversas cuestiones: la causa palestina, la condición de la mujer, las estructuras del poder, el control de los medios de comunicación, el desarraigo, la nostalgia, la pérdida, lo introspectivo, la memoria, etc.

En este sentido, podemos decir que el exilio como revela Didi Huberman en Cuando las imágenes toman posición (2008), analizando la obra de Brecht, desarrolla miradas empáticas de la historia, formulando una nueva manera de leer el tiempo y leer las imágenes. Si analizamos detenidamente Kriegsfibel, la violencia no concierne solo a una zona geográfica o un momento concreto de la historia, sino que es una cuestión global, donde Brecht genera asociaciones de imágenes que desde la narración habitual podrían ser chocantes. No obstante, vemos esa misma coherencia que se observa en la 
obra de Hatoum, donde una cama sin colchón con alambre de púas es capaz desplazar la obra de arte hacia el espectador, planteando ese tercer nivel de significancia que analiza Roland Barthes en Lo obvio y lo obtuso (1986). Aquí Barthes plantea la existencia de tres niveles de sentido en cualquier forma de expresión, especialmente la cinematográfica. Para explicar esos tres niveles Barthes se apoya en el análisis de algunos fotogramas extraídos de las películas del director de cine Serguéi M. Eisenstein como ejemplo. A través de ellas observa que puede distinguirse un primer nivel de sentido que denomina denotación y que es eminentemente informativo; un segundo nivel de significado que conlleva connotación, pues aquí el artista introduce símbolos de forma intencionada, pensando en su posible identificación por parte del espectador, recurriendo a la asociación con otras imágenes existentes en el repertorio visual (imágenes estereotipadas); y un tercer nivel de significado que identifica como "códigos desplazados", por su suplementariedad, pues son algo que el espectador percibe pero que no posee un significado intencional, por lo que contribuye a abrir el campo de la comprensión infinitamente.

Tomando como referencia dicha división de los códigos de Barthes entendemos que, en el caso de la creación artística en el exilio, el mensaje se construye mediante códigos desplazados, sobre todo si tenemos en consideración las razones de los mismos. Las narrativas exiliadas como hemos explicado anteriormente emergen de sentimientos propios del desarraigo tales como la extrañeza y el desapego del hogar. Estas experiencias generan construcciones imaginarias, nidos de lo vivido como diría Gastón Bachelard en La poética del espacio (2000) que al fin y al cabo por su forma circular representa el espacio subjetivo de cada persona. Para que seamos más ilustrativos en cuanto a la idea que estamos desarrollando recorremos a Hot Spot III, donde Hatoum como artista que ha experimentado el exilio en carne propia toma distancia del lenguaje de protesta para ofrecer una lectura global de los hechos históricos. Los tubos de acero luminosos rojos conectados a la electricidad que representan el globo terráqueo no se limitan a algunas zonas fronterizas en litigio, donde los conflictos se enquistan, como en Oriente Próximo, Afganistán, África o Asia; sino que implican que el mundo entero está constantemente atrapado en la guerra y la agitación (véase la imagen 9). En efecto, entre las dos representaciones existe una mirada codificada de los hechos que es consecuencia de la dicotomía entre la desgracia y la emancipación. La desgracia en el caso de un artista en el exilio se puede manifestar en todo lo que está relacionado con la desvinculación con el lugar y la ansiedad del extrañamiento. Por otro lado, la emancipación se presenta en 
la descripción distanciada de los acontecimientos que proporciona la experiencia de estar fuera del lugar.

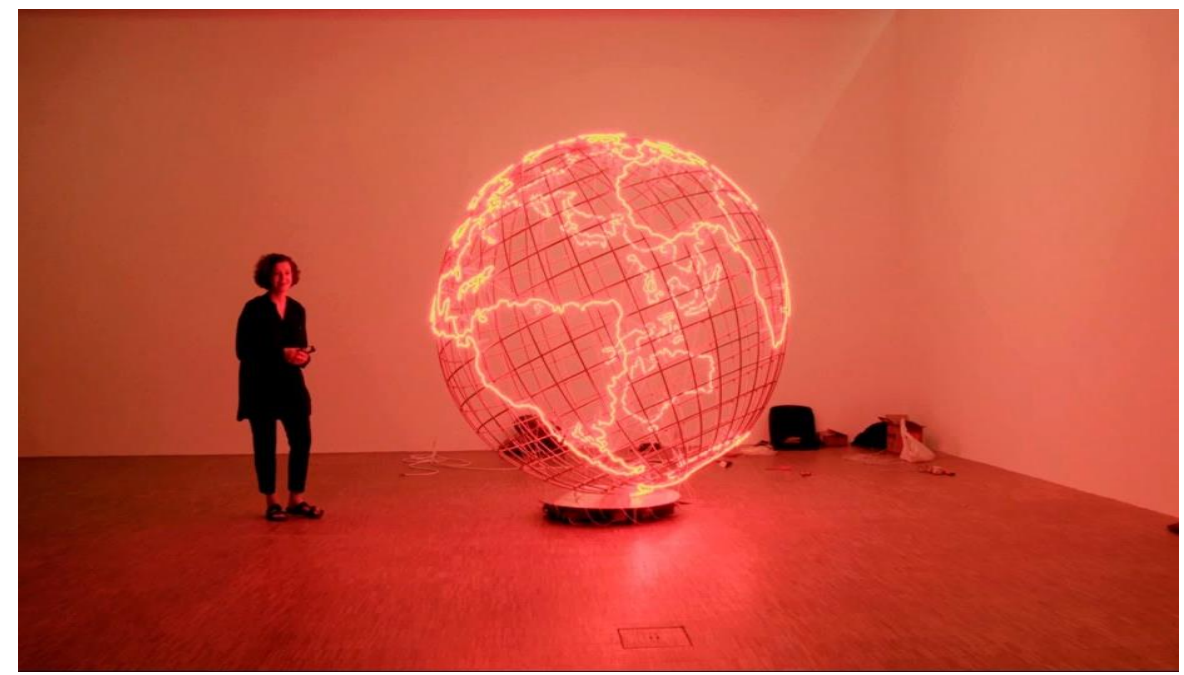

Imagen 9. Hatoum, M. (2016). Hot Spot III [en línea, acero inoxidable, tubo de neón, 234 x 223 x $223 \mathrm{~cm}$.].

\section{El Exilio como Experiencia Empática}

Ese sentimiento de pertenencia a realidades distintas contribuye, como hemos podido comprobar, a la visualización de una realidad compleja y con frecuencia difícil de mostrar: la de quien se ha visto forzada a experimentar en primera persona el desarraigo y el extrañamiento. Cuestión que recuerda a la descripción del crítico George Steiner, que afirma que todo género de obras literarias del siglo XX es hecho por exiliados. En palabras de Steiner: "Parece adecuado que aquellos que producen arte en una civilización de cuasi barbarie, que ha dejado a tantas personas sin hogar, fueron ellos mismos poetas sin alojamiento y vagabundos en el lenguaje. Excéntrico, distante, nostálgico, deliberadamente intempestivos" (Said, 2013, p. 180). Steiner se refiere a esa conexión transnacional construida desde la distancia, que también observamos en el proyecto Le pavillon de l'exil (2016) del artista franco marroquí Mounir el Fatmi, en el cual participa Hatoum. Esta propuesta trata de conectar a artistas que trabajan fuera de sus países de origen, sin perder en ningún momento esos lazos emocionales propios del extrañamiento.

Ejemplo ilustrativo de esta idea que estamos planteando es la pieza instalativa Present Tense (1996). En ella Hatoum dibuja sobre pastillas de 
jabón el mapa de Palestina, incrustando diminutas cuentas de vidrio y transformando el dibujo en un instrumento de reivindicación política. Hatoum se aferra a una causa concreta sin retratar los hechos, recurriendo a un material soluble como es el jabón, donde proporciona al espectador la posibilidad de establecer paralelismos entre la solubilidad del jabón y las diferentes modificaciones que sufre el territorio palestino. Esta fórmula de comunicación construida mediante la sencillez y el uso de la fábula establece en la obra de Hatoum esa relación íntima con el espectador que encontramos en el trabajo de Félix González-Torres, quien además trabaja sobre cuestiones de índole sociopolítico. Si bien las reivindicaciones de este artista poseen un contenido diferente a las de Hatoum, podemos detectar ciertas coincidencias en cuanto a naturaleza social y estrategia creativa. Según Hatoum:

Me gusta la actitud de González-Torres porque su trabajo es tanto estético como político. Lo que más admiro de su trabajo es que se ve muy simple, pero trata temas de vulnerabilidad del cuerpo, problemas de muerte temprana, etc., pero haciéndolo todo a través del lenguaje del arte. (Antoni, 1998)

Ese paralelismo que estamos intentando establecer entre la obra de Hatoum y la de González-Torres, sucede en Candy-Pieces (1991), una obra realizada en base a pilas de caramelos envueltos en celofán de colores vibrantes, amontonados o extendidos en el suelo de las galerías, donde González-Torres, propone simbólicamente un contrato ético con el receptor, quien tendrá que escoger entre tomar solo uno o demostrar su avaricia cogiendo montones. Es decir, a través asociaciones iconográficas, el artista logra que sea el espectador quien tenga que dar forma a la idea, interpretando y articulando la información que proporciona la obra, obligándole así a involucrarse en ella para poder tocar el fondo del mensaje.

\section{Conclusión}

A modo de conclusión, podemos decir que en la obra de Hatoum se aplica esa dialéctica entre el hombre, la sociedad y sobre uno mismo que formula Lukács en El alma y las formas (2013, p. 49), donde las estrategias narrativas empleadas, lejos de describir, proporcionan una mirada poética distanciada de "la inmediatez, ese bolo alimenticio sin procesar que es la experiencia directa" (Said, 2013, p. 87). En este sentido, estamos ante una madurez en cuanto a la lectura y la interpretación de los acontecimientos, que como hemos podido comprobar se caracteriza por la dualidad entre la representación 
autorreferencial y la distancia narrativa. En otras palabras, es una "grieta imposible de cicatrizar impuesta entre el ser humano y su lugar natal" (Said, 2013, p. 87). No obstante, el trabajo de Hatoum lejos de aferrarse al trauma asociado a la pérdida, asume su condición y su subjetividad ante los hechos y los transforma en una estrategia de comunicación poética. Es decir, mediante recursos estéticos y conceptuales que parten del contraste entre lo bello y lo desagradable, Hatoum sitúa al espectador en su experiencia vital y con ello frente a una realidad opresiva y desagradable. El espectador ante los objetos alterados se encuentra perdido y vulnerable, puesto que cualquier referencia a lo familiar y lo cotidiano es modificada, unas maletas conectadas con pelo, una cama sin colchón con una base de alambre de púas, una cocina separada con cables, unos utensilios de cocina ampliados a gran escala que amenazan y cortan, un viaje a las cavidades internas del cuerpo de la artista, unos metales al rojo vivo instalados en el espacio expositivo, entre otras de las propuestas que implican interacción. En definitiva, se trata de una experiencia compartida que remite a la existencia dañada de una artista que ha vivido en carne propia el exilio como proceso traumático difícil de cicatrizar.

\section{Referencias}

Adorno, T. (2001). Minima Moralia, Reflexiones desde la vida dañada. Taurus.

Antoni, J. (1998, abril 1). Mona Hatoum by Janine Antoni. Bomb, (63).

Barthes, R. (1986). Lo obvio y lo obtuso. Paidós.

Brecht, B. (1994). Narrativas completas, 7. Dialogos de refugiados. Alianza.

Bourriaud, N. (2007). Postproducción. Adriana Hidalgo editora.

Didi-Huberman, G. (2008). Cuando las imágenes toman posición. Machado.

Didi-Huberman, G. (2015). Fasmas. Ensayos sobre la aparición 1. Shangrila.

Jahanbegloo, R. (2011, mayo). Pensar en el exilio. Culturas: revista digital de análisis y debate sobre Oriente Próximo y el Mediterráneo, (10), 123-130.

Lauzon, C. (2009). Precarious occupations: the fragile figure of home in contemporary art. Tesis doctoral, Department of Art History and Communications Studies: McGill University. 
Lúkacs, G. (2013). Platonismo, poesía y las formas (Rudolf Kassner). En El alma y las formas. Edición Grijalbo.

Said, E. (2011). The Art of Displacement: Mona Hatoum's Logic of Irreconcilables. Quaderns de la Mediterrània, (15), 107-110.

Said, E. (2013). Reflexiones sobre el exilio. Debate.

Said, E. (2020). El poder, política y cultura. Debate.

Zambrano, M. (2019). Claros del bosque (Mercedes Gómez Blesa ed.). Madrid: Cátedra.

Yassine Chouati: Personal Investigador Contratado Predoctoral en el marco del Plan Propio de la Universidad de Sevilla y profesor en el Departamento de Dibujo de la Facultad de Bellas de la Universidad de Sevilla

Email address: ychouati@us.es

Contact Address: Facultad de Bellas de Sevilla.Calle Laraña, 3. CP: 41003, Sevilla 